\title{
Uplift of the Tibetan Plateau Influenced the Morphological Evolution of Animals
}

\author{
L. Y. Wen ${ }^{1,2}$ \\ ${ }^{1}$ College of Life Sciences, Leshan Normal University, Leshan, Sichuan, China \\ ${ }^{2}$ Key Laboratory of Colleges and Universities in Sichuan Province for Protecting Endangered Birds in the \\ Southwest Mountains, Leshan, Sichuan, China \\ Correspondence: L. Y. Wen, College of Life Sciences, Leshan Normal University, Leshan 614004, Sichuan, \\ China. Tel: 86-155-2033-0337. E-mail: lywen02@126.com
}

Received: September 23, 2014 Accepted: October 22, 2014 Online Published: November 15, 2014

doi:10.5539/jas.v6n12p244 URL: http://dx.doi.org/10.5539/jas.v6n12p244

\begin{abstract}
This is a review of the results reported by studies on the impact of the Tibetan Plateau uplift on the body size, external organs, auditory organ and sexual dimorphism of animals. In high-altitude areas, strong selection pressures, such as low temperature, oxygen deficit, high frequency of strong winds, long periods of animal inactivity, and food shortages, have led to reduction in animal size, variations in the sizes of external organs, atrophy or degradation of auditory organs and increased sexual dimorphism. These evolutionary morphological changes along a gradient in the altitude are determined by differential energy distribution in the organisms.
\end{abstract}

Keywords: Tibetan Plateau, animal morphological evolution, altitudinal gradient, low temperature, oxygen deficit, differential energy distribution

\section{Introduction}

Morphology and genetic characteristics of organisms are constantly influenced by the ecological environment (Ray, 1960). Bergmann's rule and Allen's rule describe the interplay between ecology-morphology-geography on the characteristics of an organism. Bergmann (1874) famously proposed that warm-blooded vertebrates living in cold weather conditions tend to be larger when compared to the same species living in warm weather conditions. This rule could be universally applied to all warm-blooded animals (Ashton \& Tracy, 2000; Meiri \& Dayan, 2003) along various environmental gradients (Watt et al., 2010) and some cold-blooded vertebrates and invertebrates (Lindsey, 1966; Atkinson, 1994; Atkinson \& Sibly, 1997; Arnett \& Goteli, 1999; Porter \& Hawkins, 2001; Ashton, 2002; Olalla-Tárraga et al., 2006; Timofeev, 2001). According to Allen's rule animals in colder regions tend to have shorter protruding parts of the body, such as limbs, tail and ears when compared to those living in warmer climates (Ray, 1960). Since this theory has not been tested vigorously on cold or warm-blooded animals, it is considered a "biological illusion" (Gaston et al., 1998). In addition, there are two other popular rules termed as Rensch's rule and Jordan's rule. Rensch's rule proposes that in species where males are larger than females, the difference in sexual dimorphism is increase with increasing body length. However, in species with larger females than males, the difference in sexual dimorphism is decrease with increasing body length (Rensch, 1950, 1960). According to Jordan's rule, the number of vertebrate fish in cold waters is larger than in warm waters (McDowall, 2007). Majority of the studies that tested these rules by observations were limited by defined geographic latitude and temperature gradients set at the laboratory (Atkinson, 1994; Van Voorhies, 1996), but only a few studies have examined changes over an altitude gradient such as the Tibetan Plateau, which is the highest plateau in the world. The average height of the Tibetan Plateau is 4500 m.a.s.l and, the altitude gradient formed by the uplift of the Tibetan Plateau is a naturally created site for conducting altitude based studies ( $\mathrm{Li}$ et al., 1979). Many animals living there evolve gradually with the uplift of the plateau and often encounter environmental stress, such as low temperature, hypoxia, strong solar radiation, short growing season and low food availability. Comprehensive scientific investigation on the Tibetan Plateau has been conducted since the last century by Chinese biologists focusing on the impact of the formation of the Tibetan Plateau on the evolution of animal morphology (Cao et al., 1981; Yin, 1984). Here, I review literature relevant to this topic and examine how morphological characteristics adapt to extreme environments, to determine how these animals respond to extreme environmental conditions and whether the three rules mentioned above still fit along the elevation 
gradient. This review provides useful information to understand the mechanisms regulating the morphological evolution of animals along altitudinal gradient.

\section{Body Size}

There are 102 endemic locust species in the Tibetan Plateau including 74 small sized insects (male $<20 \mathrm{~mm}$, female $<25 \mathrm{~mm}$ ). The body sizes of the same locust species living at different altitudes are different, with individuals becoming smaller as elevation increases (Yin, 1984). It is reported that the average body size of both male and female Tibetan mountain frog, Nanorana parkeri, endemic to the Tibetan Plateau and distributed in the altitudes of 2850 - 4700 m.a.s.l. (Hu, 1987) decrease significantly with increasing altitude (Ma et al., 2009). Similarly, the body sizes of both male and female Qinghai toad-headed lizard (Phrynocephalus vlangalii), which is the most widely distributed oviparous sand lizard in the Tibetan Plateau found at higher altitudes of $2289-$ 4565 m.a.s.l. are significantly smaller than the same species at lower altitudes (Jin et al., 2007). These results were also confirmed by another recent investigation on the body sizes of eight lineages of the Tibetan Plateau sand lizards along altitudinal gradient, which shows that the body size gradually becomes smaller as altitude increases (Jin et al., 2013). Further, it was found that the Tibetan snowcock, an endemic poultry species in the Tibetan Plateau, with smaller body size and, lighter weight, grow slowly at high altitudes than at low altitudes (Zhang et al., 2007a, 2007b). Such negative correlation between high altitude and animal body size also holds true for Daurian pikas (Ochotona daurica), which are smaller relatives of rabbits and hares and are distributed in the third terrace in China at an altitude of 400-4000 m.a.s.l (Liao et al., 2006) and Plateau zokor (Eospalax baileyi), a mammal endemic to the Tibetan Plateau that exists at an altitude of 3020-4550 m.a.s.1 (Zhang et al., 2012). It was proposed that food shortage and energy distribution caused by hypoxia (low oxygen pressure) and short frost-free period at high altitudes limit growth and development resulting in smaller head size of $O$. daurica at higher altitudes (Liao et al., 2006). These studies clearly demonstrate that the body sizes of most animals including invertebrates, and warm-blooded and cold-blooded vertebrates decreased as altitude increased in the Tibetan Plateau and do not support Bergmann's rule. Based on the explanation of animal morphology at different altitudes offered by various authors mentioned above, I presume that the combined effects of several factors could limit the growth and development of animals thus resulting in smaller body size. Many animals may be confined by natural features such as rivers or mountains - the new group selection might occur under natural selection processes - which results in adaptations (Grafen, 1984). Their social behaviors include altruism, cooperation, mutualism, strong reciprocity and group selection (West et al., 2007). Hence, social behaviors could involve in the morphological evolution of animals in the Tibetan Plateau. Also these factors include low temperature, hypoxic conditions, strong solar radiation, short growing season and low food availability.

I suggest that energy distribution could play a major role in limiting the growth of organisms at high altitudes because hypoxia at high altitudes could provide less energy compared to the low altitudes. Yet the amount of energy needed to maintain body activities at high altitudes is larger than at low altitudes, thereby reducing the energy distributed for animal growth and development resulting in smaller body size.

However, a contradicting result was observed in plateau pika (Ochotona curzoniae), endemic to the Tibetan Plateau at altitudes of 3164 - 4807 m.a.s.l. Both skull and body sizes of $O$. curzoniae positively correlated with geographic latitude and altitudes, consistent with Bergmann's rule. The authors proposed that the body size of $O$. curzoniae tend to increase with inclement weather and food shortage, and that $O$. curzoniae adopted an ecological strategy different from O. daurica (Lin et al., 2008)

\section{External Organs}

The external organs of animals that are directly exposed to the environment respond strongly to any changes in the environment, and thereby are subjected to environmental selection. These external organs include the integumentary skeleton of tetrapods (Vickaryous \& Sire, 2009), the wings and legs of insects, wings, legs and feet of birds, limbs of amphibians, scales, fins and tentacles of fish, scales and limbs of reptiles, and limbs and tails of mammals. The results showed that osteoderm formation is associated with structural properties of the dermis, and an extracellular matrix, for an environment which is conducive to skeletal formation (Main et al., 2005; Vickaryous \& Hall, 2008).

\subsection{Locust Wings}

Among the 102 locust species endemic to the Tibetan Plateau, 35 are wingless, accounting for $34.3 \%$ of all locusts; 30 species $(29.4 \%)$ have side wings, 22 species $(21.6 \%)$ are short-winged and only 15 species $(14.7 \%)$ are long-winged. At high altitudes, the wings of locusts in the Tibetan Plateau gradually degrade (Yin, 1984), which may be an adaptation to survival in the high altitudes because flying is an energy consuming process. Flying at high altitudes under the hypoxic and windy environment may pose a fatal risk for locusts. Therefore, 
the degradation or atrophy of locust wings serves to reduce wind resistance and energy consumption at higher altitude. In other words, high altitude selects wingless locusts. Smaller body size of populations in higher altitude also was found in carabid beetle Carabus tosanus on Shikoku Island, Japan. These may be for adaptations to different altitudes and may be important for the process of incipient speciation (Tsuchiya et al., 2012).

\subsection{Fish Scales, Pharyngeal Teeth and Tentacles}

External organs of fish surviving at high altitudes also vary from their counterparts at lower altitudes. The genus, Schizothorax, under the Cyprinidae family is distributed at altitudes of $1250-500$ m.a.s.l in the Tibetan Plateau. This genus has fine scales covering the entire body with 3 rows of pharyngeal teeth and 1-2 pairs of tentacles. However, the genus Diptychus, which is distributed at higher altitudes of 2750-3750 m.a.s.l, has partial or no body scales, 2 rows of pharyngeal teeth, and 1 pair of tentacles. At an even higher altitude of $3750-4750 \mathrm{~m}$ exists genera, Schizopygopsis and Gymnocypris, which have no body scales, 1-2 rows of pharyngeal teeth, and no tentacles (Cao et al., 1981). Another dominant fish group in the Tibetan Plateau belongs to the genus Triplophysa. Those in the Yongding River have their entire body covered with scales, in the Loess Plateau majority of their body and the tail are covered with scales, in the Tibetan Plateau the entire body is scale less and/or tail scales are hidden beneath the skin, and above 5000 m.a.s.l their entire body is scale less (Zhu, 1989). In the Tibetan Plateau, water temperature drops as altitude increases; fish living in these environments adapt to cold water temperatures and evolve hibernation, which eventually results in degradation of the body scales. Temperature decrease with increasing altitude causes changes in the biological components of aquatic ecosystems, and fishes acquired omnivorous and overeating habits, resulting in degradation of pharyngeal teeth. Since fish became omnivorous their need to forage decreased resulting in the degradation of the tentacles.

\subsection{Head, Tail and Limbs of Lizards and Mammalian Pinna Length}

Similarly, significant negative correlation is observed between the head, tail and limb lengths of the Qinghai toad-headed lizard and the altitudes it resides. Compared to Qinghai toad-headed lizard, oviparous sand lizards at low altitudes of the Tibetan Plateau have significantly reduced number of tailbones (Jin et al., 2006), which follows Allen's law. Such shorter external organs could be explained by the relationships between volume-temperature-physiology. However, the pinna length of Ochotona daurica and the midday jird (Meriones meridianus) increase significantly with increasing altitude (Liao et al., 2007; Zhao et al., 2013), which is inconsistent with Allen's rule. Liao et al. (2007) proposed that the increase in pinna length was a compensation for the decrease in the size of the auditory bulla. Such morphological compensations were found in plateau animals. For example, degradation of locust wings is compensated by the protruding pronotum side lobes, which are shaped like wings, in addition to the pads between the claws at the tarsus that are enlarged, an adaptation to jumping (Yin, 1984).

\subsection{Auditory Organs}

Animals use auditory organs to receive external information that helps them determine their behavior. Auditory organs are sensitive to external information and are strongly influenced by the ambient sound environment. Among the 102 locust species in the Tibetan Plateau, 39 have tympanal organs, accounting for $38.2 \%$ of all locusts, and 54 species (52.9\%) lack a sound producing organ (Yin, 1984). Degradation or atrophy of wings leads to degradation or atrophy of sound producing organs, which in turn leads to the loss of sound receiver. Oreolalax and Scutiger are two related genera distributed at altitudes 700-3300 m.a.s.l and 2000-5100 m.a.s.l, respectively. Significant differences are observed between these two species; while the columella of Oreolalax is rod-shaped, Scutiger has no or short columella; Oreolalax has spoon-shaped cartilage but Scutiger has no cartilage; the Eustachian tube aperture in Oreolalax is large, whereas in Scutiger it is small (Fei \& Ye, 1990). Similarly, among the three species of the genus Nanorana, Nanorana parkeri which is distributed at the highest altitude does not have columella, tympanic membrane or tympanic ring while the other two species distributed at slightly lower altitudes have columella, tympanic membrane and tympanic ring (Wen, 2004). Liao and Liu (2008) examined the relationship between vocal sac/tympanic membrane and altitudes among 162 species of anurans, and found that the auditory organs of anurans differed significantly at different altitudes; the size of the vocal sac and tympanic membrane were inversely proportional to the altitudes, while the size of the vocal sac was directly proportional to the size of the tympanic membrane. These studies demonstrate that with an increase in the altitude a corresponding decline in the auditory organs of anurans is observed. The likely cause for this is the geographic isolation; while Oreolalax lives in cold streams in deep valleys isolated by mountains, Scutiger lives in freshwater marshes in the plateau. Frogs that are physically isolated do not benefit from croaking, which is mainly performed to communicate. Also the low air density with thin air at alpine, which resulted in the slow speed of sound. Moreover, croaking in a hypoxic environment at high altitudes consumes a large amount of 
energy, posing a threat to survival. Therefore, it is conceivable that the auditory organs in amphibians at high altitudes tend to degrade compared to those living at low altitudes.

Additionally, the volume and relative volume of the auditory bulla in $O$. daurica significantly decrease as altitude increases (Liao et al., 2007). Hypoxia, strong wind and food shortage at high altitudes make the auditory bulla small, which leads to decreased hearing at high altitudes. As a compensation for hearing loss and a mechanism for body temperature regulation, the pinna length of $O$. daurica increase as altitude increases (Liao et al., 2007).

\section{Sexual Dimorphism}

Jin et al. (2013) examined Rensch's rule on sexual dimorphism by studying eight lineages of Phrynocephalus in the Tibetan Plateau. Their results showed differences in the body sizes of females and males in eight different lineages. With the increasing altitude, the body length both male and female get decreasing, and female is longer than male. The logarithmic regression of the male body length to female body length slope coefficient was less than 1, which contradicts Rensch's rule (Figure 1A). The authors proposed that the fertility selection in females at different altitudes and the plasticity of gender differences led to variations in body size between the genders of sand lizards along an altitudinal gradient that deviates from Rensch's rule.
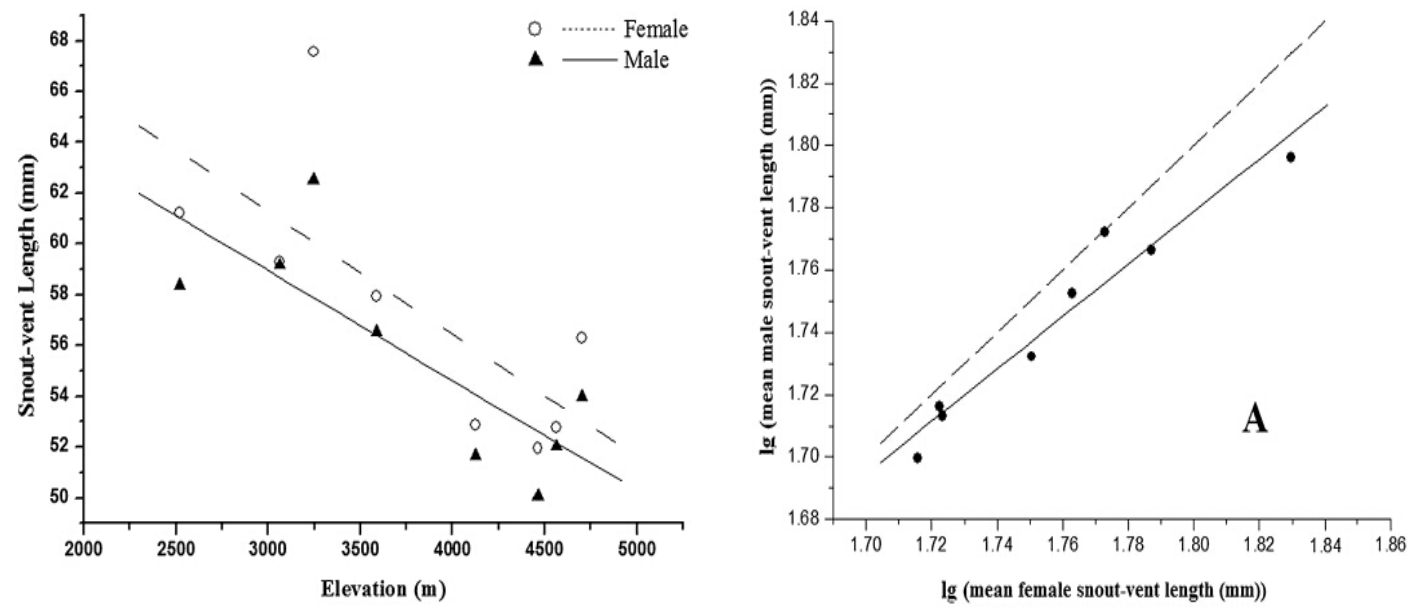

Figure 1. Regression analyses of mean snout-vent length on mean elevation of Phrynocephalus from the Tibetan Plateau. (A) is present $\mathrm{Lg}$ (mean male) plotted against lg (mean female) for Phrynocephalus (solid squares). The solid line is fitted to these data. Slopes are significantly smaller than 1 (dashed line). The dashed line represents a size ratio of 1 (size of males $=$ size of females). From Jin et al. (2013)

In summary, I have reviewed the studies that reported changes in species morphology at different altitudes in the Tibetan Plateau. It is apparent that environmental factors, such as temperature, oxygen, wind power and food resources influence the evolution of animal morphology, and the use and disuse of organs in various species. Some animals however, showed characteristics that deviated from the general rules of morphology and sexual dimorphism. The mechanism causing these effects needs to be investigated.

\section{Acknowledgements}

I gratefully acknowledge funding for this research by the Natural Science Fund of China (No.31372171), Department of Applied Basic Research of Sichuan Province (2013JY0073), and Building Plan for Scientific Research Innovation Team of Leshan Normal University.

\section{References}

Arnett, A. E., \& Gotelli, N. J. (1999). Geograp hic variation in life history traits of the ant lion Myrmeleon immmaculatus: evolutionary implications of Bergmann's rule. Evolution, 53, 1180-1188. http://dx.doi.org/10.2307/2640821

Ashton, K. G. (2002). Do amphibians follow Bergmann's rule? Canadian Journal of Zoology, 80, 708-706. http://dx.doi.org/10.1139/z02-049

Ashton, K. G., \& Tracy, M. C. (2000). de Queiroz A. Is Bergmann's rule valid for mammals? The American 
Naturalist, 156, 390-415. http://dx.doi.org/10.1086/303400

Atkinson, D. (1994). Temperature and organism size a biological law for ectotherms? Advances in Ecological Research, 25, 1-58. http://dx.doi.org/10.1016/S0065-2504(08)60212-3

Atkinson, D., \& Sibly, R. M. (1997). Why are organisms usually bigger in colder environments? Making sense of a life history puzzle. Trends in Ecology \& Evolution, 12, 235-239. http://dx.doi.org/10.1016/S0169-5347(97)01058-6

Bergmann, C. (1847). Ueber die verhältnisse der wärmeökon-omie der thiere zu ihrer grösse. Gott Stud, 3 , 595-708.

Cao, W. X., Chen, Y. Y., Wu, Y. F., \& Zhu, S. Q. (1981). Origin and evolution of schizothoracine fishes in relation to the upheaval of the Xizang Plateau. In Tibetan Expedition Team of the Chinese Academy of Science (Ed.), Studies on the period, amplitude and type of the uplift of the Qinghai-Xizang Plateau. Beijing, BJ: Science Press.

Fei, L., \& Ye, C. Y. (1990). The intergenus phylogenetic relationship and differentiation of Asian spadefoot toads and their relation to the formation of the Tibetan Plateau. Current Zoology, 36, 420-428.

Gaston, K. J., Blackburn, T. M., \& Spicer, J. I. (1998). Rapoport's rule: time for an epitaph? Trends in Ecology \& Evolution, 13, 70-74. http://dx.doi.org/10.1016/S0169-5347(97)01236-6

Grafen, A. (1984). Natural selection, kin selection and group selection. Behavioural ecology: an evolutionary approach, 2.

Hu, S. Q. (1987). Amphibia-Reptilia of Xizang. Beijing, BJ: Science Press.

Jin, Y. T., Li, J. Q., \& Liu, N. F. (2013). Elevation-related variation in life history traits among Phrynocephalus lineages on the Tibetan Plateau: do they follow typical squamate ecogeographic patterns? Journal of Zoology, 290, 293-301. http://dx.doi.org/10.1111/jzo.12042

Jin, Y. T., Liu, N. F., \& Li, J. L. (2007). Elevational variation in body size of Phrynocephalus vlangalii in the North Tibet Plateau. Belgian Journal Zoology, 137, 197-202. Retrieved from https://www.naturalsciences.be/fr/en/institute/associations/rbzs_website/bjz/back/pdf/BJZ\%20137(2)/Volum e\%20137(2),\%20pp.\%20197-202.pdf

Jin, Y. T., Tian, R. R., \& Liu, N. F. (2006). Altitudinal variations of morphological characters of Phrynocephalus sand lizards: on the validity of Bergmann's and Allen's rules. Acta Zoologica Sinica, 52, 838-845. Retrieved from http://www.actazool.org/paperdetail.asp $2 \mathrm{id}=5196 \&$ volume $=52 \&$ number $=5 \&$ bgpage $=838 \&=$ endpage 8 $45 \&$ year $=2006 \&$ month $=10$

Li, J. J., Wen, S. X, Zhang, Q. S., Wang, F. B., Zheng, B. X., \& Li, B. Y. (1979). A discussion on the period, amplitude and type of the uplift of the Qinghai-Xizang Plateau. Science Sincia, 22, 1314-1328. Retrieved from http://www.cnki.com.cn/Article/CJFDTotal-JAXG197911007.htm

Liao, J. C., \& Liu, N. F. (2008). Altitudinal variations of acoustic organs in anurans: A case study from China. Italian Journal of Zoology, 75, 125-134. http://dx.doi.org/10.1080/11250000701878773

Liao, J. C., Zhang, Z. B., \& Liu, N. F. (2006). Altitudinal variation of skull size in Daurian pika (Ochtona daurica Pallas, 1868). Acta Zoologica Academiae Scientiarum Hungaricae, 52, 319-329. Retrieved from http://www.gfsoso.com/scholar?q=Altitudinal+variation + of + skull + size + in + Daurian+pika $+\% 28$ Ochtona + da urica+Pallas\%2C+1868\%29.+

Liao, J. C., Zhang, Z. B., \& Liu, N. F. (2007). Effects of altitudinal change on the auditory bulla in Ochotona daurica (Mammalia, Lagomorpha). Journal of Zoological Systematics and Evolutionary Research, 45, 151-154. http://dx.doi.org/10.1111/j.1439-0469.2006.00401.x

Lin, G., Ci, H., Zhang, T., \& Su, J. (2008). Conformity to bergmann's rule in the plateau pika (Ochotona curzoniae Hodgson, 1857) on the Qinghai - Tibetan Plateau. Acta Zoologica Academiae Scientiarum Hungaricae, 54, 411-418. Retrieved from http://actazool.nhmus.hu/54/4/Azh54_4_Lin.pdf

Lindsey, C. C. (1966). Body size of poikilotherm vertebrates at different latitudes. Evolution, 20, 456-465. http://dx.doi.org/10.2307/2406584

Ma, X. Y., Lu, X., \& Meril, J. (2009). Altitudinal decline of body size in a Tibetan frog. Journal of Zoology, 279, 364-371. http://dx.doi.org/10.1111/j.1469-7998.2009.00627.x

Main, R. P., de Ricqlès, A., Horner, J. R., \& Padian, K. (2005). The evolution and function of thyreophoran 
dinosaur scutes: Implications for plate function in stegosaurs. Paleobiology, 31, 291-314. http://dx.doi.org/10.1666/0094-8373(2005)031\%5B0291:TEAFOT\%5D2.0.CO;2

McDowall, R. (2007). Jordan's and other ecogeographical rules, and the vertebral number in fishes. Journal of Biogeography, 35, 501-508. http://dx.doi.org/10.1111/j.1365-2699.2007.01823.x

Meiri, S., \& Dayan, T. (2003). On the validity of Bergmann's rule. Journal of Biogeography, 30, $331-351$. http://dx.doi.org/10.1046/j.1365-2699.2003.00837.x

Olalla-Tárraga, M. Á., Rodríguez, M. Á., \& Hawkins, B. A. (2006). Broad-scale patterns of body size in squamate reptiles of Europe and North America. Journal of Biogeography, 33, 781-793. http://dx.doi.org/10.1111/j.1365-2699.2006.01435.x

Porter, E. E., \& Hawkins, B. A. (2001). Latitudinal gradients in colony size for social insects: Termites and an s show different patterns. The American Naturalist, 157, 97-106. http://dx.doi.org/10.1086/317006

Ray, C. (1960). The application of Bergmann's and Allen's rules to the poikilotherms. Journal of Morphology, 106, 85-108. http://dx.doi.org/10.1002/jmor.1051060104

Rensch, B. (1950). Die Abhängigkeit der relativen Sexualdif-ferenz von der Körpergrösse. Bonn Zool Beitr, 1, 58-69.

Rensch, B. (1960). Evolution above the species level. New York, NY: Columbia University Press.

Timofeev, S. F. (2001). Bergmann's Principle and Deep-Water Gigantism in Marine Crustaceans. Biology Bulletin, 28, 646-650. http://dx.doi.org/10.1023/A:1012336823275

Tsuchiya, Y. L., Takami, Y., Okuzaki, Y., \& Sota, T. (2012). Genetic differences and phenotypic plasticity in body size between high- and low-altitude populations of the ground beetle Carabus tosanus. Journal of Evolutionary Biology, 25(9), 1835-1842. http://dx.doi.org/10.1111/j.1420-9101.2012.02568.x

Van Voorhies, W. A. (1996). Bergmann size clines: A simple explanation for their occurrence in ectotherms. Evolution, 50, 1259-1264. http://dx.doi.org/10.2307/2410666

Vickaryous, M. K., \& Hall, B. K. (2008). Development of the dermal skeleton in Alligator mississippiensis (Archosauria, Crocodylia) with comments on the homology of osteoderms. Journal of morphology, 269, 398-422. http://dx.doi.org/10.1002/jmor.10575

Vickaryous, M. K., \& Jean-Yves, S. (2009). The integumentary skeleton of tetrapods: origin, evolution, and development. Journal of Anatomy, 214(4), 441-464. http://dx.doi.org/10.1111/j.1469-7580.2008.01043.x

West, S. A., Griffin, A. S., \& Gardner, A. (2007). Social semantics: altruism, cooperation, mutualism, strong reciprocity and group selection. Journal of Evolutionary Biology, 20(2), 415-432. http://dx.doi.org/10.1111/j.1420-9101.2006.01258.x

Watt, C., Mitchell, S., \& Salewski, V. (2010). Bergmann's rule: a concept cluster? Oikos, 119, 89-100. http://dx.doi.org/10.1111/j.1600-0706.2009.17959.x

Wen, X. M. (2004). Studies on the Osteology of Genus Nanorana (Anura: Ranidae). Master's research papers.

Yin, X. C. (1984). Grasshoppers and Locusts from Qinghai- Xizang Plateau of China. Beijing, BJ: Science Press.

Zhang, H., Wu, C. X., Chamba, Y. Z., Ling, Y., \& Ji, S. L. (2007b). Influence of altitude on growth curves in Tibetan chicken and its hybrid. Journal of China Agriculture, 12, 40-44. Retrieved from http://en.cnki.com.cn/Article_en/CJFDTOTAL-NYDX200702007.htm

Zhang, H., Wu, C. X., Chamba, Y. Z., Ling, Y., \& Li, J. Y. (2007a). Influence of Altitude on Weight and Carcass Characteristics in Tibetan Chicken and Its Crossing Combination. Acta Ecologiae Animalis Domastic, 28, 48-52. Retrieved from http://en.cnki.com.cn/Article_en/CJFDTOTAL-JCST200702013.htm

Zhang, T. Z., Nevo, E., Tang, L. Z., Su, J. P., \& Lin, G. H. (2012). Plateau zokors on the Qinghai-Tibetan Plateau follow Bergmann's rule latitudinally, but not altitudinally. Mammalian Biology, 77, $108-112$. http://dx.doi.org/10.1016/j.mambio.2011.08.005

Zhao, L. M., Wang, Y., Liu, N. F., \& Liao, J. C. (2013). Effects of Change in Altitude on the Auditory Bulla of Midday Gerbil, Meriones meridianus. Pakistan Journal of Zoology, 45, 581-588. Retrieved from http://zsp.com.pk/pdf45/581-588\%20_1_\%20PJZ-1160-12\%202-5-13.pdf

Zhu, S. Q. (1989). The Loaches of the Subfamily Nemacheilinae in China (Cypriniformes: Cobitidae) 
(Cypriniformes: Cobitidae). Nanjing, NJ: Jiangsu Science and Technology Publishing House.

\section{Copyrights}

Copyright for this article is retained by the author(s), with first publication rights granted to the journal.

This is an open-access article distributed under the terms and conditions of the Creative Commons Attribution license (http://creativecommons.org/licenses/by/3.0/). 